\title{
Phototherapy Radiometer with AS7262 Sensor
}

\author{
Ichwan Syahrul Bahtiar", Andjar Pudji, I Dewa Gede Hari Wisana \\ Department of Electromedical Engineering, Poltekkes Kemenkes Surabaya \\ Jl. Pucang Jajar Timur No. 10, Surabaya, 60245, Indonesia \\ \#ichwan.syahrul27@gmail.com, andjar.pudji@gmail.com, hariwisana88@gmail.com
}

\begin{abstract}
The phototherapy is a device used in hyperbilirubinemia therapy by using blue light radiation with ranges between $425 \mathrm{~nm}$ $475 \mathrm{~nm}$. The effectiveness of hyperbilirubinemia therapy depends on the amount of energy emitted by light which expressed in $\mu W / \mathrm{cm} 2$. The purpose of this study is to develop a low-cost and high accuracy Phototherapy radiometer. Measurement of blue light irradiance using the AS7262 sensor which can measure the irradiance of visible light with a wavelength of $450 \mathrm{~nm}, 500 \mathrm{~nm}, 550 \mathrm{~nm}, 570 \mathrm{~nm}, 600 \mathrm{~nm}$, $650 \mathrm{~nm}$ with relative responsiveness of 1 time at each wavelength. SD card memory is used to save measurement data of irradiance so that it can be processed later. Based on the blue light irradiance data collected the smallest error value is $0,40 \%$ at a distance of $10 \mathrm{~cm}$ while the biggest error value is $9,01 \%$ at a distance of $30 \mathrm{~cm}$. After testing the entire system, the device can be used according to its function and purpose.
\end{abstract}

\section{Keywords-Phototherapy Radiometer; Blue Light; AS7262 Sensor}

\section{INTRODUCTION}

Health equipment in its use to patients, both direct and indirect goals is to save human life. Problems that are often encountered today are equipment that has an improper output so that it will cause a less precise diagnosis and therapeutic dose. Health equipment that has been used in a certain period of time and has never been carried out maintenance, causing a decrease in the level of reliability of the equipment, security is not guaranteed and the physical condition of the equipment is not controlled. Phototherapy is a device that uses light or light exposure with certain wavelengths that come from polychromatic polarized light, lasers, LEDs, fluorescent lights, dichroic lights or very bright full-spectrum light. Light is given for a specified amount of time and, in some cases, at certain times of the day. Phototherapy utilizes a blue light lamp that has a wavelength of 400-500 nm with a frequency of $606-668 \mathrm{~Hz}$ for therapy or treatment in infants suffering from jaundice (hyperbilirubinemia). The effectiveness of the treatment of the yellow baby disease depends on the amount of energy emitted by light expressed by radiation in $\mu \mathrm{W} / \mathrm{cm} 2$ [1]. However, visible light radiation can cause the same photochemical damage as UVR. This effect is most evident at wavelengths of around 435$440 \mathrm{~nm}$ and is sometimes called Blue-Light hazard [2]. Any kind of optical radiation with sufficient intensity can cause damage to the eyes and skin including photo conjunctivitis and photokeratitis.

In Abu Abdillah et al. [3] research, entitled "Rancang Bangun Phototherapy Radiometer Menggunakan Sensor TCS3200" has successfully detected the intensity of radiation from blue light phototherapy. The TCS3200 sensor is capable of capturing blue light with a wavelength of 400-500 nm with a frequency of $606-668 \mathrm{~Hz}$, but the TCS3200 sensor only has a relative responsivity of 0.5 times on the blue filter. Related research was also developed by Ganjar et al. [4]; they made a phototherapy radiometer using light intensity sensor BH1750 and SD Card memory to save the blue light value. The research was focused on the distribution of phototherapy lamp lights and the correlation between the intensity of the lights with the lifetime of a phototherapy lamp.

Based on those problems, the objective of this study is to develop a Phototherapy Radiometer based on minimum system ATMega328 equipped with SD card memory and Nextion 3,2" TFT display. Furthermore, the phototherapy radiometer also can measurement 6 visible light (violet, blue, green, yellow, orange and red) into a color graph that displayed in Nextion TFT.

\section{MAterials AND METHODS}

\section{A. Experimental Setup}

This study used double surface phototherapy with the criteria the lamp that has a wavelength of $400-500 \mathrm{~nm}$. The data collection is repeated for 5 times at distance $10 \mathrm{~cm}, 20 \mathrm{~cm}, 30 \mathrm{~cm}$, and $40 \mathrm{~cm}$

\section{1) Materials and Tool}

This study is used as an Adafruit AS7262 6-channel visible light sensor. The minimum system ATMega328 was used to read a blue light value from the sensor. SD Card Memory with a 16 Mbyte was used to save the blue light value every 1 minute. A Dale40 (Fluke, USA) was used to calibrate the blue light value.

\section{2) Experiment}

In this study, after the design was completed then this device was tested using double surface phototherapy and compared to Dale40 with all range $(10,20,30$, and $40 \mathrm{~cm})$. Each setting, the output of the phototherapy radiometer was saved to SD Card every 1 minute. 


\section{B. The Diagram Block}

In this research, the sensor is placed at a distance of 10, 20, 30 and $40 \mathrm{~cm}$ from the phototherapy lamp as shown in Fig. 1. The minimum system was used to communicate with the sensor using SCL and SDA pin. The blue light value was displayed in Nextion TFT and the value was saved to the SD card for further data analysis.

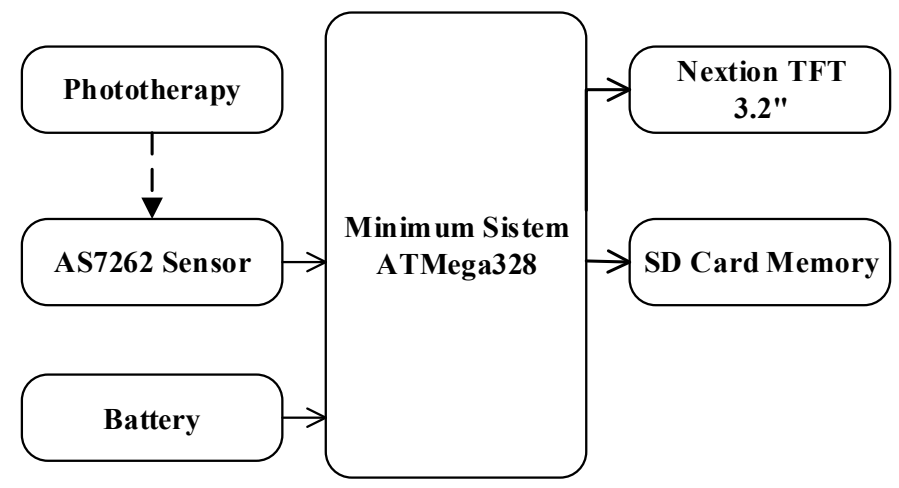

Fig. 1. The diagram block of the Phototherapy Radiometer

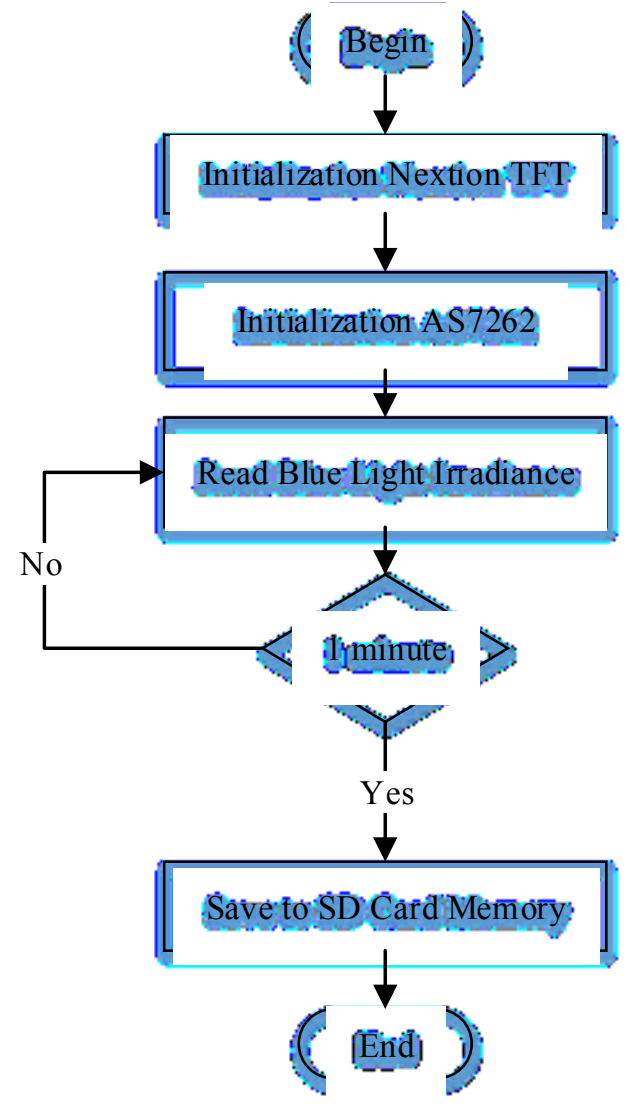

Fig. 2. The flowchart of the Arduino program

\section{The Flowchart}

The Arduino program was built based on the flowchart as shown in Fig. 2. After the initialization of the Nextion TFT, the sensor read the value of blue light. If the measurement is 1 minute, then the data was saved to the SD card memory.

\section{The Full Circuit}

A minimum system ATMega328 circuit as shown in Fig. 3 was using crystal $16 \mathrm{MHz}$ and 2 capacitor $22 \mathrm{pF}$ to generates a clock for microcontroller. A buzzer was connected to A1. The sensor was connected to SCL and SDA.

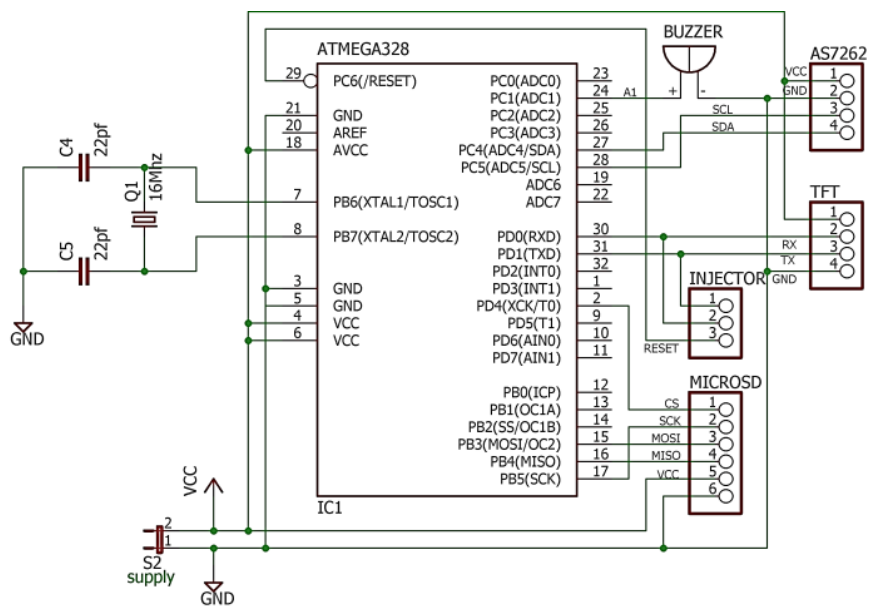

Fig. 3. Minimum system ATMega328

\section{RESULTS}

In this study, the phototherapy radiometer has been tested using double surface phototherapy. The result shows that the recording is feasible to measurement the blue light value.

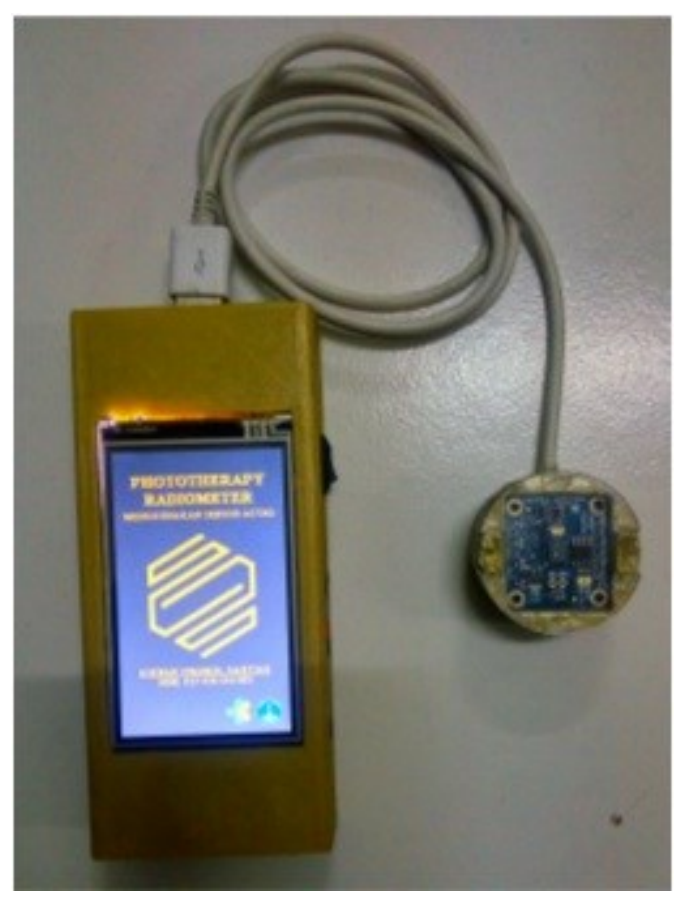

Fig. 4. Phototherapy radiometer design 


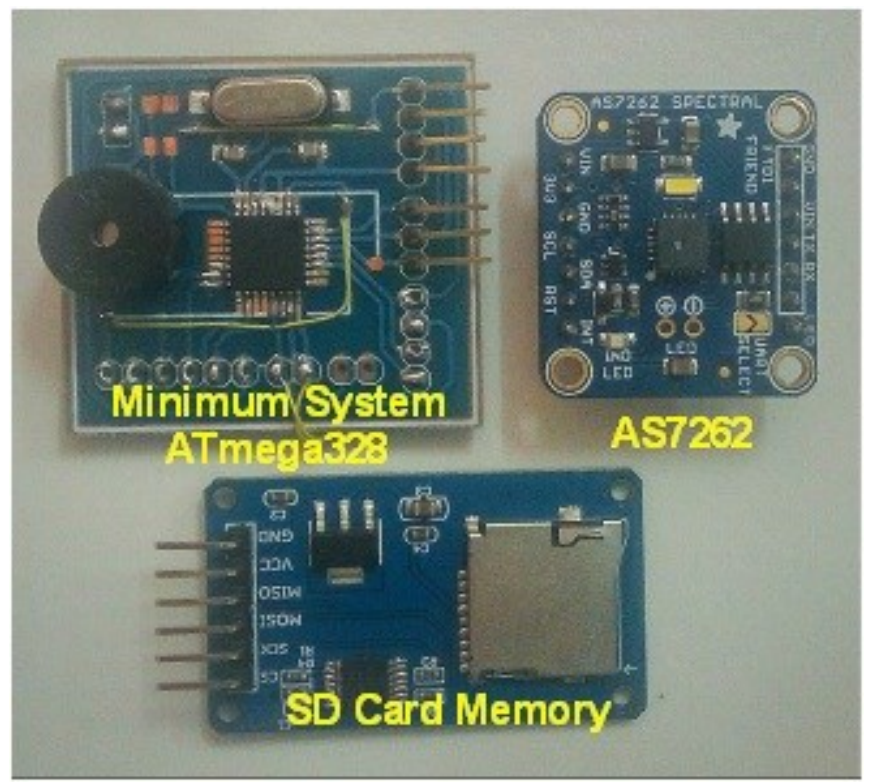

Fig. 5. The digital part of the phototherapy radiometer

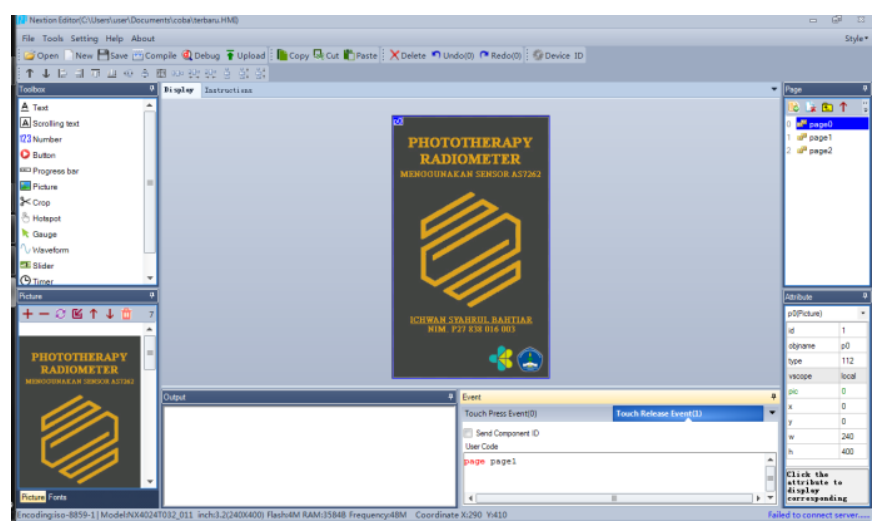

Fig. 6. Design the display on Nextion Editor

\section{1) The Phototherapy Radiometer Design}

The photograph of the device and digital part of the phototherapy radiometer was shown in Fig. 4 and Fig. 5, respectively. The digital part consisted of the minimum system ATMega328 which is the main board of phototherapy radiometer device, sensor AS7262, Nextion TFT display, and SD card memory module in which to save the blue light value every 1 minute.

\section{2) The Listing Program for Arduino Phototherapy Radiometer}

In this paper, the software was using Arduino programming. The listing program for Arduino as shown in the Listing Program 1. Which consisted of the program to send the data to the serial and displayed on Nextion TFT display.
Listing program 1. Program to send the irradiance to Nextion display

$/ /======$ blue light value $======$

String Command = "t0.txt=|""+String(irradiance) $+" \mid " "$;

Serial.print(Command);

Serial.write(0xff);

Serial.write(0xff);

Serial.write(0xff);

$/ /======$ graph $=======$
$/ /======$ violet $=======$

Serial.print("j0.val=");

Serial.print(violet);

Serial.write(0xff);

Serial.write(0xff);

Serial.write(0xff);

//=====-blue======

Serial.print("j1.val=");

Serial.print(biru);

Serial.write(0xff);

Serial.write(0xff);

Serial.write(0xff);

$/ /======$ green $=====$

Serial.print("j2.val=");

Serial.print(hijau);

Serial.write(0xff);

Serial.write(0xff);

Serial.write(0xff);

$/ /======$ yellow $======$

Serial.print("j3.val=");

Serial.print(kuning);

Serial.write(0xff);

Serial.write(0xff);

Serial.write(0xff);

$/ /======$ orange

Serial.print("j4.val=");

Serial.print(oranye);

Serial.write(0xff);

Serial.write(0xff);

Serial.write(0xff);

$/ /======\mathrm{red}======$

Serial.print("j5.val=");

Serial.print(merah);

Serial.write(0xff);

Serial.write(0xff);

Serial.write(0xff); 
In order for the phototherapy radiometer able to save the measurement value of blue light, an SD card was used to save the blue light value every 1 minute. The Listing program was shown as Listing Program 2.

Listing Program 2. Program to save the Irradiance in SD Card

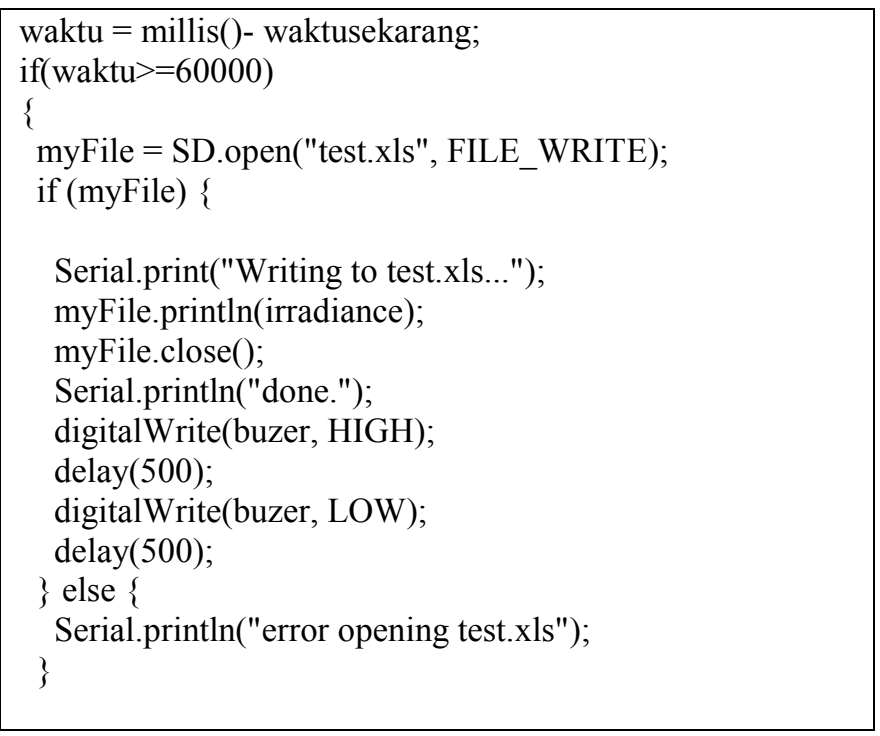

The Listing Program 3. was used to read the raw value of blue light measurement and convert to the irradiance.

Listing Program 3. Program to read the raw value of blue light

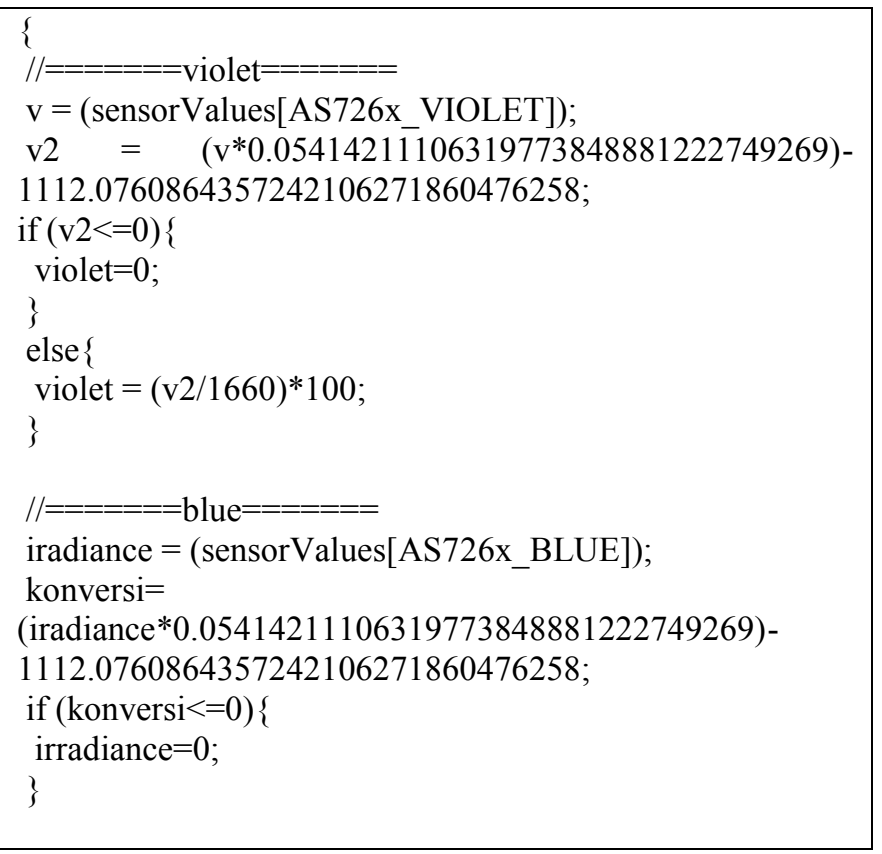

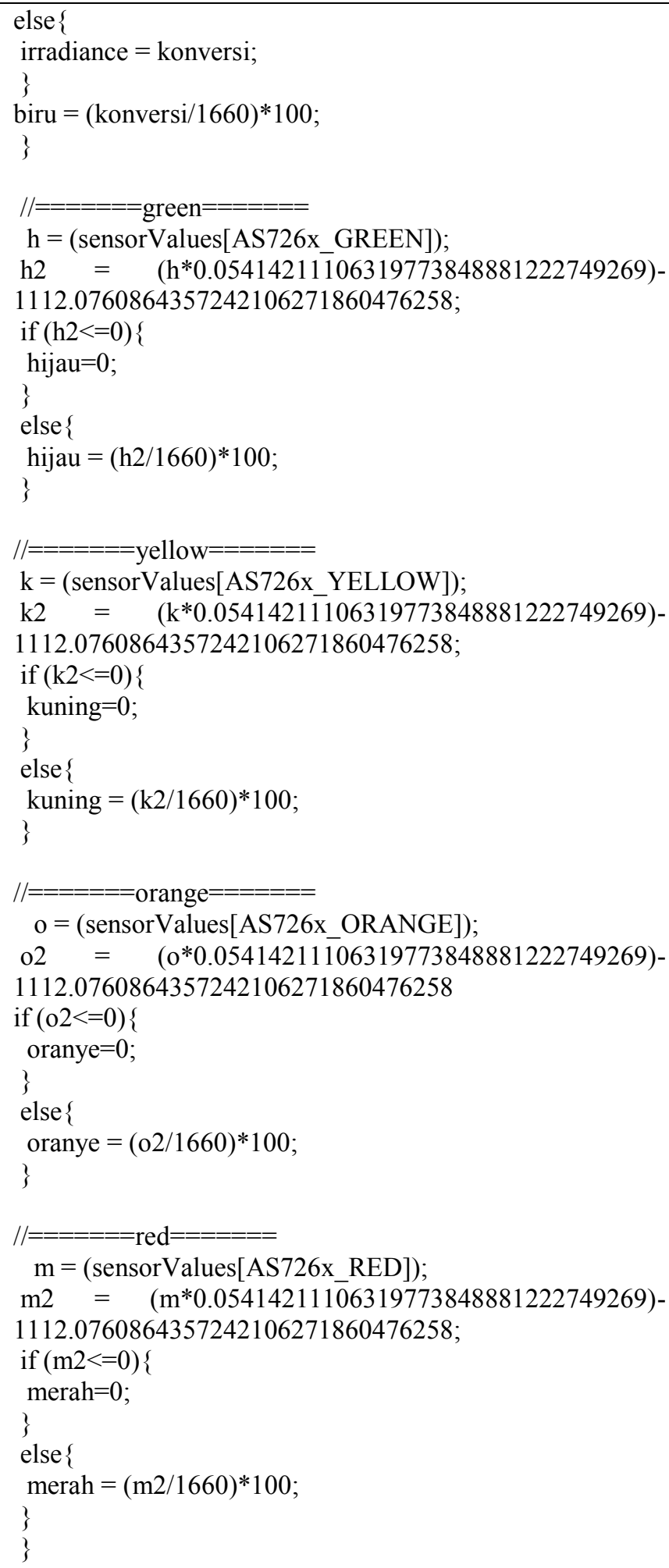




\section{3) Phototherapy Radiometer Output Display}

The device was tested using double surface phototherapy with distance 10, 20, 30, and $40 \mathrm{~cm}$.

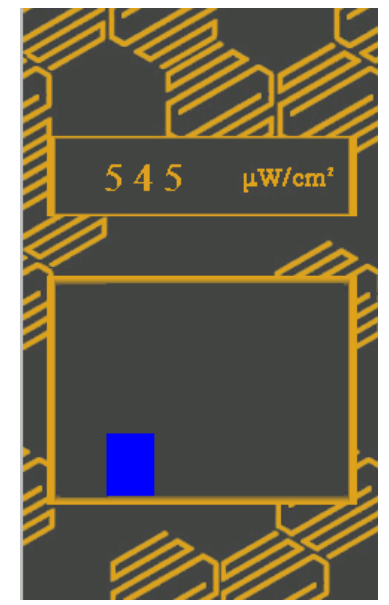

Fig. 7. The measurement of blue light value $(40 \mathrm{~cm})$

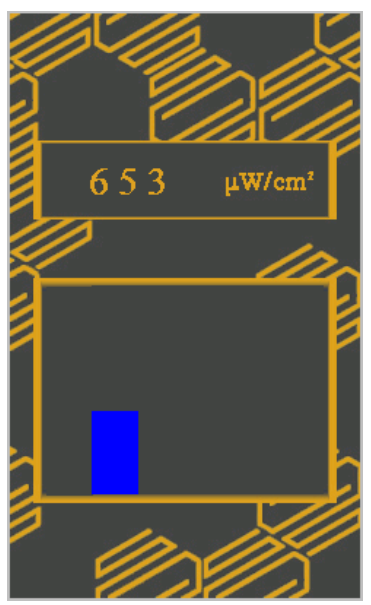

Fig. 8. The measurement of blue light value $(30 \mathrm{~cm})$

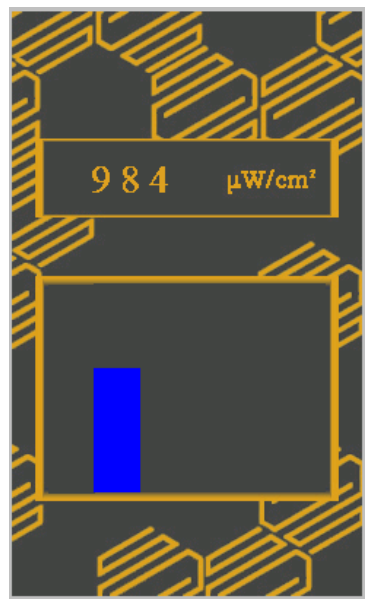

Fig. 9. The measurement of blue light value $(20 \mathrm{~cm})$

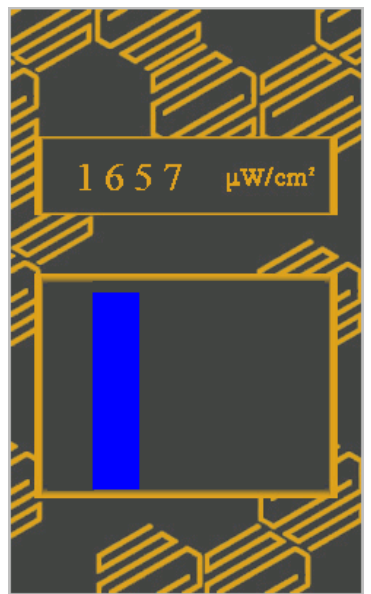

Fig. 10. The measurement of blue light value $(10 \mathrm{~cm})$

4) The Error of irradiance $(\mu \mathrm{W} / \mathrm{cm} 2)$ value

The validation of the blue light value shown in the display was compared with the Dale40 device. The error was showed in Table I.

TABLE I. THE ERROR OF MEASUREMENT FOR A BLUE LIGHT VALUE BETWEEN THE DESIGN AND CALIBRATOR.

\begin{tabular}{ccc}
\hline Distance & Error & Ua \\
\hline $10 \mathrm{~cm}$ & $0,40 \%$ & 1,17 \\
$20 \mathrm{~cm}$ & $8,32 \%$ & 1,56 \\
$30 \mathrm{~cm}$ & $9,01 \%$ & 1,39 \\
$40 \mathrm{~cm}$ & $2,25 \%$ & 1,36 \\
\hline
\end{tabular}

\section{DISCUSSION}

The phototherapy radiometer design has been examined and test completely in this study. Based on the measurement of the blue light value output, the resulted device can read the blue light value that has a wavelength of 400-500 $\mathrm{nm}$ with distance 10, 20, 30 , ad $40 \mathrm{~cm}$.

By comparing the output of the phototherapy radiometer and the Dale40, It was shown that there is a different value in each distance. This is reasonable because the sensor used by Dale 40 has a cosine diffuser that can focus the light into photodiode so the photodiode can read the maximum light. The Error of blue light value between the design and Dale40 showed the value of $0.0225 \pm 1.36$ at $40 \mathrm{~cm}$. This error value indicated that the phototherapy radiometer is feasible to be the measurement value of the phototherapy device. In order the phototherapy radiometer able to work in jaundice therapy then this design needs a battery with high capacity.

The performance of this work was also compared to other works. Abu Abdillah found that his phototherapy radiometer had the biggest error was $10.6 \mu \mathrm{W} / \mathrm{cm} 2$ and the smallest error was $1.8 \mu \mathrm{W} / \mathrm{cm} 2[3]$. 


\section{Conclusion}

This study has demonstrated the development of the phototherapy radiometer to measurement the phototherapy irradiance with real-time. This study was built based on the minimum system ATMega328, sensor AS7262, Nextion TFT display, and SD card memory module. This study has proofed that the accuracy is feasible to be used to measurement blue light phototherapy in real-time and the data recording can be read from the SD card memory.

\section{REFERENCES}

[1] S. M. Reda, K. A. Mohammad, and S. M. El-faramawy, "Construction and characterization of a phototherapy radiometer for optical radiation measurements," Indian J. Pure Appl. Phys., vol. 56, no. 5, pp. 379-382, 2018.

[2] European Commission, Non-binding guide to good practice for implementing Directive 2006/25/EC (Artificial optical radiation). 2011.

[3] Abu Abdillah, Priyambada Cahya Nugraha, Endang Dian Setyoningsih, "Rancang Bangun Phototherapy Radiometer Menggunakan Sensor TCS3200," pp. 1-87, 2017.

[4] Ganjar Heru Purnomo, Bedjo Utomo, Triana Rahmawati, "Phototeraphy Radiometer Dengan Penyimpanan Data Pengukuran Pada SDCard," pp. $1-7,2018$. 